\title{
Impact of machining on the flexural fatigue strength of glass and polycrystalline CAD/CAM ceramics
}

\author{
Sara Fraga ${ }^{a}$, Marina Amaral ${ }^{b}$, Marco Antônio Bottino $^{c}$, \\ Luiz Felipe Valandro ${ }^{d}$, Cornelis Johannes Kleverlaan ${ }^{e}$, \\ Liliana Gressler May ${ }^{f, *}$ \\ a Post-Graduate Program in Dental Science, Universidade Federal de Santa Maria, Santa Maria, Rio Grande do Sul, \\ Brazil \\ b Post-Graduate Program in Dentistry, Universidade de Taubaté, Taubaté, São Paulo, Brazil \\ c Department of Dental Materials and Prosthodontics, São Paulo State University, São José dos Campos, São Paulo, \\ Brazil \\ d Department of Restorative Dentistry, Universidade Federal de Santa Maria, Santa Maria, Rio Grande do Sul, Brazil \\ e Department of Dental Materials, Academic Centre for Dentistry Amsterdam (ACTA), University of Amsterdam and \\ Vrije University Amsterdam, Amsterdam, The Netherlands \\ ${ }_{\mathrm{f}}$ Department of Restorative Dentistry, Universidade Federal de Santa Maria, Santa Maria, Rio Grande do Sul, Brazil
}

\section{A R T I C L E I N F O}

\section{Article history:}

Received 31 January 2017

Received in revised form

21 June 2017

Accepted 27 July 2017

\section{Keywords:}

Computer-aided design

Computer-aided manufacturing

Fatigue

Biaxial flexural strength

Piston-on-three ball

Roughness

Zirconia

Leucite glass ceramic

Lithium disilicate

\begin{abstract}
A B S T R A C T
Objectives. To assess the effect of machining on the flexural fatigue strength and on the surface roughness of different computer-aided design, computer-aided manufacturing (CAD/CAM) ceramics by comparing machined and polished after machining specimens.

Methods. Disc-shaped specimens of yttria-stabilized polycrystalline tetragonal zirconia (YTZP), leucite-, and lithium disilicate-based glass ceramics were prepared by CAD/CAM machining, and divided into two groups: machining $(\mathrm{M})$ and machining followed by polishing (MP). The surface roughness was measured and the flexural fatigue strength was evaluated by the step-test method $(n=20)$. The initial load and the load increment for each ceramic material were based on a monotonic test $(n=5)$. A maximum of 10,000 cycles was applied in each load step, at $1.4 \mathrm{~Hz}$. Weibull probability statistics was used for the analysis of the flexural fatigue strength, and Mann-Whitney test $(\alpha=5 \%)$ to compare roughness between the M and MP conditions.

Results. Machining resulted in lower values of characteristic flexural fatigue strength than machining followed by polishing. The greatest reduction in flexural fatigue strength from MP to M was observed for Y-TZP (40\%; M=536.48 MPa; MP $=894.50 \mathrm{MPa})$, followed by lithium disilicate $(33 \% ; \mathrm{M}=187.71 \mathrm{MPa} ; \mathrm{MP}=278.93 \mathrm{MPa})$ and leucite $(29 \% ; \mathrm{M}=72.61 \mathrm{MPa}$; $\mathrm{MP}=102.55 \mathrm{MPa}$ ). Significantly higher values of roughness (Ra) were observed for $\mathrm{M}$ compared to MP (leucite: $\mathrm{M}=1.59 \mu \mathrm{m}$ and $\mathrm{MP}=0.08 \mu \mathrm{m}$; lithium disilicate: $\mathrm{M}=1.84 \mu \mathrm{m}$ and $\mathrm{MP}=0.13 \mu \mathrm{m} ; \mathrm{Y}$-TZP: $\mathrm{M}=1.79 \mu \mathrm{m}$ and $\mathrm{MP}=0.18 \mu \mathrm{m})$.
\end{abstract}

Abbreviations: CAD/CAM, computer-aided design computer-aided manufacturing; FDPs, fixed dental prostheses; SCG, slow crack growth; Y-TZP, yttria-stabilized polycrystalline tetragonal zirconia; Ra, average surface roughness ( $\mu \mathrm{m})$; Rz, arithmetic mean peak-to-valley height $(\mu \mathrm{m}) ; \lambda c$, cut-off value.

* Corresponding author at: Marechal Floriano Peixoto St. 1184, 97015-372, Santa Maria, RS, Brazil. Fax: +55 5532209272.

E-mail addresses: sara.odonto@yahoo.com.br (S. Fraga), marinamaral_85@yahoo.com.br (M. Amaral), bottino@fosjc.unesp.br (M.A. Bottino), lfvalandro@gmail.com (L.F. Valandro), c.kleverlaan@acta.nl (C.J. Kleverlaan), liligmay@gmail.com (L.G. May). http://dx.doi.org/10.1016/j.dental.2017.07.019 0109-5641/๑ 2017 The Academy of Dental Materials. Published by Elsevier Ltd. All rights reserved. 
Significance. Machining negatively affected the flexural fatigue strength of CAD/CAM ceramics, indicating that machining of partially or fully sintered ceramics is deleterious to fatigue strength

@ 2017 The Academy of Dental Materials. Published by Elsevier Ltd. All rights reserved.

\section{Introduction}

Recent improvements in the mechanical properties of dental ceramic systems and the implementation of computer-aided design, computer-aided manufacturing (CAD/CAM) technology in restorative dentistry have widely contributed to the increase in the use of all-ceramic restorations as an alternative for satisfying the high esthetic demand of patients [1].

A great variety of ceramic materials are available for CAD/CAM, with each differing in microstructure, mechanical behavior, and also machining mode [2,3]. Feldspar-, leucite-, and lithium disilicate-based ceramics are commonly available in a full sintered stage for hard machining [4]. These materials contain high volumes of glassy phases and, consequently, have a lower fracture toughness compared to that of polycrystalline ceramics $[5,6]$. In lithium disilicate glass ceramics, the presence of lithium disilicate crystals promotes crack deflection, which improves its fracture strength [7]. Therefore, this material is recommended not only for the manufacture of veneers, inlays, onlays, and anterior and posterior crowns, as with leucite glass ceramics [8], but also for implant superstructures of single-tooth restorations [9].

Yttria-stabilized polycrystalline tetragonal zirconia (Y-TZP) can be milled either from pre-sintered blocks (soft machining) followed by sintering at high temperature, or from fully-sintered blocks (hard machining) [10]. Soft machining is the most used process to manufacture Y-TZP restorations, since hard machining is more time consuming and requires tougher cutting devices $[10,11]$. Y-TZP ceramics exhibit a transformation toughening mechanism that acts to resist crack propagation. It involves the transformation of metastable tetragonal crystallites to the monoclinic phase at the crack tip, which, accompanied by a volumetric expansion, induces compressive stresses, hindering further crack propagation [12]. It may be used as infrastructure for crowns and fixed dental prostheses (FDPs) covered by glass-ceramic [3] or as monolithic full-contour restorations $[13,14]$, besides being indicated for implant abutments [3].

Despite the promising clinical success rates, framework fracture of all-ceramic restorations is still a technical problem [15-17], which may warrant additional costs to the patient and to the dentist for the replacement of the restoration. In a recent systematic review, with the inclusion of 67 clinical studies, 5-year framework fracture rates of up to $18.4 \%, 5.5 \%$, and $1.7 \%$ were reported for single crowns made of feldspathic ceramic, reinforced glass ceramic (including both leucite- and lithium disilicate-based glass ceramics), and densely sintered zirconia, respectively [16]. When multiple-unit fixed dental prostheses were considered, these rates increased up to $15.3 \%$ for reinforced glass ceramic and up to $3.2 \%$ for densely sintered zirconia [17]. There seem to be a remarkable difference between leucite- and lithium disilicate-reinforced ceramics in terms of mechanical behavior, which is reflected in the survival rates of the restorations. For a mean period of 4.5 years, the fracture rate of leucite-based single crowns was estimated in $3.8 \%$, with molars showing the highest fracture rate $(6.7 \%)$ [18]; while the fracture rate of lithium disilicate single crowns was $1.22 \%$, over a period of 3.5 years [15].

Due to the brittle nature of ceramics, their fracture strength is strongly influenced by the presence of defects, which can be considered particularly critical when located at the zones of tensile stress concentration $[19,20]$. Fractographic analysis of clinically failed all-ceramic restorations [19,21,22] and finite element analysis $[23,24]$ showed that the cementation surface of all-ceramic crowns concentrates tensile stress, and that defects on this surface may be the origin of fracture in failed restorations $[19,21,22]$. Besides, the cervical margins of all-ceramic restorations seem to have an important role in the fracture initiation, as indicated by fractographic studies $[25,26]$. Therefore, procedures that affect the intaglio surface and the cervical margins of all-ceramic restorations must be investigated regarding their impact on the ceramic strength.

Despite reducing processing defects, once the CAD/CAM blocks are produced in a standard process, machining induces a complex network of events in the ceramic, resulting in radial and lateral cracks, chipping, subsurface damage, and residual stresses [27-30]. Hard machining resulted in damage to the ceramic surface, and reduced the biaxial flexural strength of a leucite glass ceramic by approximately $27 \%$ [31]. Soft machining also resulted in surface damage and significantly reduced the strength of zirconia, which may result in unexpected failures at stresses much lower than the ideal strength of the material [32]. Kelly et al. [33] reported that the defects introduced by the CEREC ${ }^{\circledR}$ (Sirona Dental Systems Gmbh, Germany) CAD/CAM system appeared to be the origin of the failure in ceramics subjected to a uniaxial bending test.

It is important to consider that in the oral environment, allceramic restorations are subject to many challenges, such as cyclic loads, humidity, $\mathrm{pH}$, and temperature variations. Consequently, failure tends to occur due to fatigue [34]. Ceramics are susceptible to a slow and stable crack growth (SCG) when subjected to stresses below the critical value, especially in the presence of water. This phenomenon can eventually lead to strength degradation over time, decreasing the lifetime of dental prostheses and appears to be most related to the ceramic microstructure [35].

Therefore, considering the increasing use of CAD/CAM technology in restorative dentistry, in which the machining process introduces new features in the cementation surface of ceramic restorations, and the susceptibility of ceramic materials to fatigue, this study aimed to assess the effect of CAD/CAM machining on the biaxial flexural fatigue strength and on 
the surface roughness of a leucite-based glass ceramic, a lithium disilicate-based glass ceramic, and a yttria-stabilized polycrystalline tetragonal zirconia (Y-TZP). The experimental hypothesis was that, for all ceramics investigated, machining would result in lower values of biaxial flexural fatigue strength and in higher values of roughness when compared to polishing after machining.

\section{Materials and methods}

Table 1 describes the materials used in this study with manufacturers data for chemical composition and physical properties $[8,9,36]$.

\subsection{Machining of ceramic discs by CAD/CAM}

Disc-shaped ceramic specimens were prepared by machining in a CEREC inLab MC XL milling unit (Sirona Dental Systems Gmbh, Germany), according to the methodology described by Fraga et al. [31] (Fig. 1), using three different ceramic materials: leucite-based glass ceramic (IPS Empress CAD, C14, Ivoclar Vivadent AG, Liechtenstein) milled in a fully-sintered stage; lithium disilicate-based glass ceramic (IPS e.max CAD, LT, C14, Ivoclar Vivadent AG, Liechtenstein) milled in a pre-crystallized stage ("blue stage"); and Y-TZP (Vita In-Ceram YZ, Vita Zahnfabrik, Germany) milled in a partially-sintered stage.

Two sets of diamond burs were used in the machining of each type of ceramic material (Table 1). Fifty discs were obtained from lithium disilicate and from Y-TZP blocks, and the set of burs was changed after machining with 25 th disc. Forty discs were obtained from leucite-based glass ceramic material, and the set of burs was changed after machining with the 20th disc. Ten discs of lithium disilicate and Y-TZP were used in a monotonic strength test. Less specimens of leucite-glass ceramic were produced, since the monotonic strength data were taken from Fraga et al. [31]. The machining order and the set of burs used were recorded for each individual disc and the effect of these variables on the surface roughness and on the flexural fatigue strength of each material was evaluated afterwards.

Each block of leucite $(12.0 \mathrm{~mm} \times 14.0 \mathrm{~mm} \times 18.0 \mathrm{~mm})$ and lithium disilicate $(12.4 \mathrm{~mm} \times 14.5 \mathrm{~mm} \times 18.0 \mathrm{~mm})$ resulted in one disc, while each block of Y-TZP $(15.5 \mathrm{~mm} \times 19 \mathrm{~mm} \times 39 \mathrm{~mm})$ resulted in two discs. Immediately after machining, the leucite and lithium disilicate discs measured approximately $13.5 \mathrm{~mm}$ in diameter and $1.4 \mathrm{~mm}$ in thickness; the no-sintering Y-TZP discs measured approximately $18 \mathrm{~mm}$ in diameter and $1.8 \mathrm{~mm}$ in thickness, since the software (CEREC inLab 3D, version 4.0, Sirona Dental Systems Gmbh, Germany) automatically compensated the sintering shrinkage expected for Y-TZP (approximately $20-25 \%)$.

\subsection{Experimental groups}

After machining, the discs of each ceramic material were randomly divided into two groups, using the software Random Allocator (www.random.org): (1) machining (M) and (2) machining followed by polishing (MP). Therefore, the present study consisted of six experimental groups, assigned according to the material (leucite glass ceramic, lithium disilicate glass ceramic and Y-TZP) and the treatment performed on the bottom surface of the discs (machining - M, and machining followed by polishing - MP).

In the MP groups, polishing was performed manually under water-cooling on the bottom surface of the discs by a single trained operator, using 400,600, and 1200 grit silicon carbide paper for leucite and lithium disilicate, and 1200 grit silicon carbide paper for Y-TZP. It was removed a thickness of $80 \mu \mathrm{m}$ from the machined surface to eliminate the irregularities introduced by machining [29,31]. A micrometer (210 MAP, Starrett, USA) was used to control the depth of removal.

The final thickness of all specimens was adjusted on the upper surface of the discs, using 240, 400, 600, and 1200 grit silicon carbide paper for leucite glass ceramic and lithium disilicate (grounded until $1.2 \mathrm{~mm}$ thickness), and 1200 grit silicon carbide paper for Y-TZP (grounded until $1.5 \mathrm{~mm}$ thickness).

After these procedures, lithium disilicate specimens were submitted to heat treatment in a Vita Vacumat 6000 MP furnace (Vita Zahnfabrik, Germany) to promote full crystallization and Y-TZP specimens were densely sintered in Vita Zyrcomat furnace, following the protocols indicated by the manufacturers. The final diameter of the discs was $13.5 \mathrm{~mm}$, and the final thickness was $1.31 \pm 0.01 \mathrm{~mm}$ for leucite glass ceramic, $1.30 \pm 0.01 \mathrm{~mm}$ for lithium disilicate, and $1.29 \pm 0.01$ for Y-TZP discs.

\subsection{Measurement of the surface roughness}

The roughness of the bottom surface of each disc was measured prior to the mechanical tests, using a contact stylus profilometer (SJ-410, Mitutoyo, Japan).

The average surface roughness $(\mathrm{Ra}, \mu \mathrm{m})$ and the arithmetic mean peak-to-valley height $(\mathrm{Rz}, \mu \mathrm{m})$ values were determined using the average of three measurements, transversal to the machining path. The sampling length was equivalent to a value fivefold the cut-off value $(\lambda c)$, as defined according to ISO 4287:1997 [37], using the Ra values recorded at a first reading as a reference. Thereafter, the roughness of the MP leucite glass ceramic specimens was evaluated using $\lambda \mathrm{c}=0.25 \mathrm{~mm}$ (tabulated value for $0.02<\mathrm{Ra} \leq 0.1 \mathrm{~mm}$ ), resulting in a sampling length of $1.25 \mathrm{~mm}$. The roughness of the other groups was measured using $\lambda \mathrm{c}=0.8 \mathrm{~mm}$ (tabulated value for $0.1<\mathrm{Ra} \leq 2.0 \mathrm{~mm}$ ), resulting in a sampling length of $4 \mathrm{~mm}$. In addition to the use of the correct cut-off value, a Gaussian filter was employed to differentiate between shape defects and roughness profile.

\subsection{Monotonic biaxial flexural strength}

Prior to the fatigue test, the monotonic biaxial flexural strength was determined for lithium disilicate and Y-TZP specimens, in both conditions: machining $(\mathrm{M})$ and machining followed by polishing (MP) $(n=5)$. For the leucite groups ( $\mathrm{M}$ and $\mathrm{MP}$ ), the data regarding the monotonic biaxial flexural strength were taken from Fraga et al. [31].

The test was performed using a piston-on-three ball assembly, according to the ISO 6872:2008 [38], in a universal testing machine (DL-1000 Emic, Brazil), without water. 


\begin{tabular}{|c|c|c|c|c|c|c|}
\hline \multirow[t]{2}{*}{ Ceramic } & \multirow[t]{2}{*}{ Brand name; Manufacturer } & \multirow[t]{2}{*}{ Chemical composition $^{\mathrm{a}}$} & \multirow{2}{*}{$\begin{array}{c}\text { Vickers hardness }^{a} \\
\text { (GPa) }\end{array}$} & \multirow{2}{*}{$\begin{array}{l}\text { Fracture toughness }^{\mathrm{a}} \\
\qquad(\mathrm{MPa} \sqrt{ } \mathrm{m})\end{array}$} & \multicolumn{2}{|c|}{ Machining } \\
\hline & & & & & Set of bur & Manufacturer \\
\hline $\begin{array}{l}\text { Leucite-based glass } \\
\text { ceramic }\end{array}$ & $\begin{array}{l}\text { IPS Empress CAD; } \\
\text { IvoclarVivadent }\end{array}$ & $\begin{array}{l}\mathrm{SiO}_{2} 60-65 \mathrm{wt} \% \\
\mathrm{Al}_{2} \mathrm{O}_{3} 16-20 \mathrm{wt} \% \\
\mathrm{~K}_{2} \mathrm{O} 10-14 \mathrm{wt} \% \\
\mathrm{Na}_{2} \mathrm{O} \text { 3.5-6.5 wt\% } \\
\text { other oxides } \\
0.5-7 \mathrm{wt} \% \\
\text { pigments } 0.2-1 \mathrm{wt} \%\end{array}$ & 6.2 fully sintered & 1.3 & $\begin{array}{l}\text { Step bur } 12 \mathrm{~S} \\
\text { (left side of the Cerec } \\
\text { machine) } \\
\text { Cylinder pointed bur } \\
12 \mathrm{~S} \text { (right side of the } \\
\text { Cerec machine) }\end{array}$ & $\begin{array}{l}\text { Sirona Dental } \\
\text { Systems }\end{array}$ \\
\hline $\begin{array}{l}\text { Lithium } \\
\text { disilicate-based } \\
\text { glass ceramic }\end{array}$ & $\begin{array}{l}\text { IPS e.max CAD; } \\
\text { IvoclarVivadent }\end{array}$ & $\begin{array}{l}\mathrm{SiO}_{2} 57-80 \mathrm{wt} \% \\
\mathrm{Li}_{2} \mathrm{O} 11-19 \mathrm{wt} \% \\
\mathrm{~K}_{2} \mathrm{O} 0-13 \mathrm{wt} \% \\
\mathrm{P}_{2} \mathrm{O}_{5} 0-11 \mathrm{wt} \% \\
\mathrm{ZrO}_{2} 0-8 \mathrm{wt} \% \\
\mathrm{ZnO} 0-8 \mathrm{wt} \% \\
\text { other and coloring } \\
\text { oxides } 0-12 \mathrm{wt} \%\end{array}$ & $\begin{array}{l}5.4 \text { partially } \\
\text { crystallized } \\
5.8 \text { fully crystallized }\end{array}$ & $2.0-2.5$ & $\begin{array}{l}\text { Step bur } 12 \mathrm{~S} \\
\text { (left side of the Cerec } \\
\text { machine) } \\
\text { Cylinder pointed bur } \\
12 \mathrm{~S} \\
\text { (right side of the } \\
\text { Cerec machine) }\end{array}$ & $\begin{array}{l}\text { Sirona Dental } \\
\text { Systems }\end{array}$ \\
\hline $\begin{array}{l}\text { Yttria-stabilized } \\
\text { polycrystalline } \\
\text { tetragonal zirconia } \\
\text { (Y-TZP) }\end{array}$ & $\begin{array}{l}\text { Vita In-Ceram } 2000 \\
\text { YZ for inLab; } \\
\text { Vita Zahnfabrik }\end{array}$ & $\begin{array}{l}\mathrm{ZrO}_{2} 91-94 \mathrm{wt} \% \\
\mathrm{Y}_{2} \mathrm{O}_{3} 4-6 \mathrm{wt} \% \\
\mathrm{HfO}_{2} 2-4 \mathrm{wt} \% \\
\mathrm{Al}_{2} \mathrm{O}_{3}<0.1 \mathrm{wt} \% \\
\mathrm{SiO}_{2}<0.1 \mathrm{wt} \% \\
\mathrm{Na}_{2} \mathrm{O}<0.1 \mathrm{wt} \%\end{array}$ & 11.77 fully sintered & 5.9 & $\begin{array}{l}\text { Step bur } 20 \\
\text { (left side of the Cerec } \\
\text { machine) } \\
\text { Cylinder pointed bur } \\
20 \\
\text { (right side of the } \\
\text { Cerec machine) }\end{array}$ & $\begin{array}{l}\text { Sirona Dental } \\
\text { Systems }\end{array}$ \\
\hline
\end{tabular}




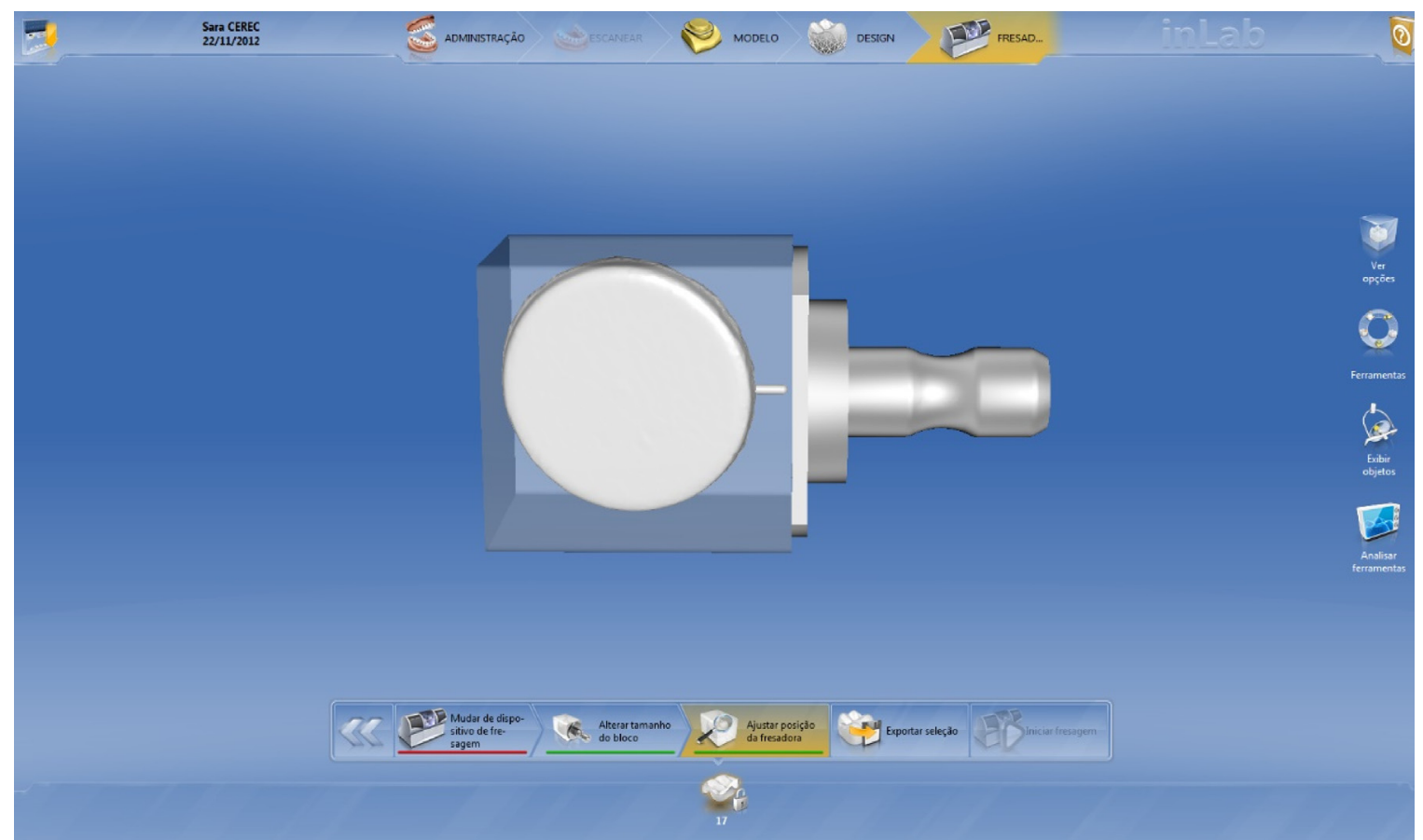

Fig. 1 - CEREC inLab 3D ${ }^{\circledR}$ software interface (version 4.0) showing a disc-shaped specimen, inside the ceramic block, ready for machining.

The bottom surface of the disc-referred to as the M or MP surface-was positioned on the top of the three steel spheres ( $2.5 \mathrm{~mm}$ in diameter, $120^{\circ}$ apart, and forming a circle of $10 \mathrm{~mm}$ diameter), with a load applied at a rate of $1 \mathrm{~mm} / \mathrm{min}$, perpendicular to the center of the top surface of the disc, by a circular cylinder steel piston with a $1.4 \mathrm{~mm}$ diameter flat tip. The fracture strength, in MPa, was calculated using Eqs. (1)-(3) [38].

$\sigma_{m}=-0.2387 \mathrm{P}(\mathrm{X}-\mathrm{Y}) / \mathrm{b}^{2}$

$X=(1+v) \ln (B / C)^{2}+[(1-v) / 2](B / C)^{2}$

$Y=(1+v)\left[1+\ln (A / C)^{2}\right]+(1-v)(A / C)^{2}$

where $P$ is the load at fracture $(\mathrm{N}), \mathrm{b}$ is the disc thickness $(\mathrm{mm})$, $A$ is the support ball radius $(5 \mathrm{~mm}), B$ is the radius of the tip of the piston $(0.7 \mathrm{~mm})$, and $C$ is the specimen radius $(6.75 \mathrm{~mm})$. A specific Poisson ratio (v) was used for each ceramic material ( 0.20 for the leucite glass-ceramic; 0.21 for the lithium disilicate glass-ceramic; 0.26 for the Y-TZP), based on the mean values obtained in the resonant ultrasound spectroscopy (RUS) methodology described by Belli et al. [39].

\subsection{Flexural fatigue test}

The biaxial flexural fatigue strength of the groups $(n=20)$ was evaluated via the step-test method in an adapted fatigue tester (Fatigue Tester, ACTA, The Netherlands) using the same piston-on-three ball configuration [38] in water.

The step-test consists in to subject the specimen to a prescribed number of cycles at each of a sequence of increasing stress levels, until the failure of the specimen. To start a steptest, a stress level below to the expected material fatigue strength is selected. The specimen is then tested at that stress level until either failure occurs or the run-out at a previously set number of cycles is achieved. If failure occurs, the stress level and the number of cycles are recorded. If run-out occurs, the stress level is increased by a preselected stress increment and the same specimen is run again at the new stress level. Again, if the specimen fails, the data are recorded; and if runout occurs, the stress level is again increased for a new run using the same specimen. This procedure is continued until the specimen does fail [40].

Cyclic load was applied at a frequency of $1.4 \mathrm{~Hz}$. The maximum number of cycles at each load step was set in 10,000 cycles. If the specimen survived the 10,000 cycles, the stress level was increased by a fixed load increment in the same specimen. An individual loading protocol was established for each type of ceramic based on the results of the monotonic test. For leucite glass ceramic groups, the cycling started with $30 \mathrm{~N}$. If the specimen survived the 10,000 cycles, the load was increased successively by a step of $10 \mathrm{~N}$ until the failure of the specimen. In lithium disilicate groups, an initial load of $60 \mathrm{~N}$ was applied in addition to successive steps of $20 \mathrm{~N}$ until failure, while for Y-TZP specimens, an initial load of $300 \mathrm{~N}$ was applied, followed by successive steps of $50 \mathrm{~N}$.

The software was adjusted to register the load and the number of cycles corresponded to the fracture of the specimen.

The maximum biaxial flexural fatigue load $\left(\mathrm{L}_{\mathrm{E}}\right)$ supported by each specimen was calculated according to the equation described by Nicholas [41] (Eq. (4)): 
$L_{E}=L_{0}+\Delta L\left(\frac{N_{\text {fail }}}{N_{\text {life }}}\right)$

where $\mathrm{L}_{0}$ is the previous maximum biaxial flexural fatigue load that did not result in failure, $\Delta \mathrm{L}$ is the load step increase, $\mathrm{N}_{\text {fail }}$ is the number of cycles to failure at the failure load step $\left(\mathrm{L}_{0}+\Delta \mathrm{L}\right)$, and $\mathrm{N}_{\text {life }}$ is the defined cyclic fatigue life (10,000 cycles). The linear interpolation concept embodied in Eq. (4) considers that damage accumulation might be a linear function of cycles [41]. Eqs. (1)-(3) were used to calculate the biaxial flexural fatigue strength value, in $\mathrm{MPa}$, correspondent to $\mathrm{L}_{\mathrm{E}}$ for each specimen.

\subsection{Field emission scanning electron microscopy analysis (FESEM)}

To evaluate the effectiveness of the polishing protocol in removing machining damage, one extra disc of each group was analyzed in a field emission scanning electron microscope (FESEM) (Inspect F50, FEI, USA). To assess the cross-sectional surface of the machined discs (M groups) and of the machined and polished discs (MP groups), the extra samples were included in acrylic resin and cut, perpendicularly to the $\mathrm{M}$ and MP surfaces, using a diamond saw at low speed (Isomet 1000, Buehler, Lake Buff, USA). After cutting, the samples were detached from the acrylic resin and had their cross-sectional surfaces polished $(400,600,800$, and 1200 grit silicon carbide paper) and sputter-coated with gold-palladium for FESEM.
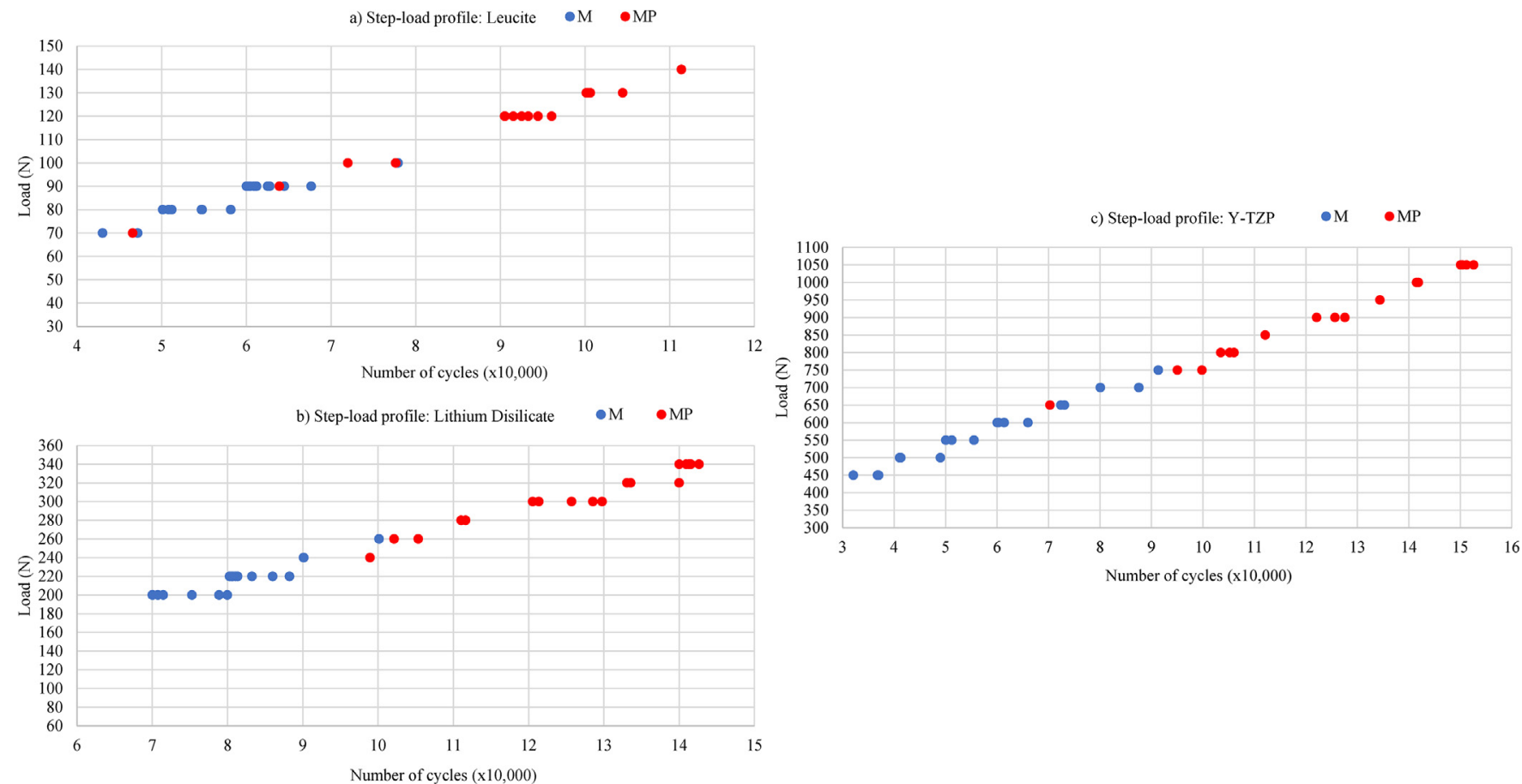

Fig. 2 - Step-load profile of leucite (a), lithium disilicate (b), and yttria-stabilized polycrystalline tetragonal zirconia (Y-TZP) (c) groups. The blue circles represent the fractured specimens of the machining $(\mathrm{M})$ groups; the red circles represent the fractured specimens of the machining followed by polishing (MP) (control) groups. (For interpretation of the references to color in this figure legend, the reader is referred to the web version of this article.) 
Table 2 - Mean and standard deviation (MPa) for the values of the monotonic and of the flexural fatigue strength test; Weibull analysis of the fatigue data (characteristic flexural fatigue strength - $\sigma_{0}$; Weibull modulus - m; $95 \%$ confidence intervals [CI]); and roughness values ( $\mathrm{Ra}$ and $\mathrm{Rz}$ ) for the ceramics investigated in both conditions: $\mathrm{M}$ - machining; $\mathrm{MP}$ (control) - machining followed by polishing.

\begin{tabular}{|c|c|c|c|c|c|c|c|}
\hline \multirow[t]{2}{*}{ Ceramic } & \multirow{2}{*}{$\begin{array}{l}\text { Surface } \\
\text { condition }\end{array}$} & \multirow{2}{*}{$\begin{array}{l}\text { Monotonic } \\
\text { flexural } \\
\text { strength } \\
(\mathrm{Mean}(\mathrm{SD}) \\
(\mathrm{MPa}))\end{array}$} & \multirow{2}{*}{$\begin{array}{l}\text { Fatigue } \\
\text { flexural } \\
\text { strength } \\
(\mathrm{Mean}(\mathrm{SD}) \\
(\mathrm{MPa}))\end{array}$} & \multicolumn{2}{|l|}{$\begin{array}{l}\text { Weibull } \\
\text { analysis of } \\
\text { the fatigue } \\
\text { data }\end{array}$} & \multicolumn{2}{|c|}{ Roughness } \\
\hline & & & & $\begin{array}{l}\text { Characteristic } \\
\text { fatigue strength } \\
{[95 \% \mathrm{CI}](\mathrm{MPa})}\end{array}$ & $\begin{array}{l}\text { Weibull } \\
\text { modulus } \\
{[95 \% \mathrm{CI}]}\end{array}$ & $\begin{array}{l}\text { Ra Mean } \\
(\mathrm{SD})(\mu \mathrm{m})\end{array}$ & $\begin{array}{l}\text { Rz Mean } \\
(\mathrm{SD})(\mu \mathrm{m})\end{array}$ \\
\hline \multirow[t]{2}{*}{ Leucite } & M & $122.12(14.11)^{\mathrm{a}}$ & $69.50(7.15)$ & $72.61^{\mathrm{A}}[69.28-76.04]$ & $11.71^{\mathrm{A}}[7.41-15.76]$ & $1.59^{\mathrm{A}}(0.17)$ & $9.83^{\mathrm{A}}(0.90)$ \\
\hline & MP & $166.48(25.81)^{\mathrm{a}}$ & $96.02(14.72)$ & $102.55^{\mathrm{B}}[95.00-110.56]$ & $7.18^{\mathrm{A}}[4.48-9.71]$ & $0.08^{\mathrm{B}}(0.03)$ & $0.51^{\mathrm{B}}(0.17)$ \\
\hline \multirow[t]{2}{*}{ Lithium disilicate } & $\mathrm{M}$ & $269.52(26.27)$ & $180.71(15.61)$ & $187.71^{\mathrm{A}}[180.30-195.30]$ & $13.62^{\mathrm{A}}[8.63-18.34]$ & $1.84^{\mathrm{A}}(0.18)$ & $11.07^{A}(1.00)$ \\
\hline & MP & $479.39(58.88)$ & $267.10(26.87)$ & $278.93^{\mathrm{B}}[266.04-292.22]$ & $11.61^{\mathrm{A}}[7.35-15.62]$ & $0.13^{\mathrm{B}}(0.06)$ & $0.73^{\mathrm{B}}(0.32)$ \\
\hline \multirow{2}{*}{$\begin{array}{l}\text { Yttria-stabilized } \\
\text { polycrystalline } \\
\text { tetragonal zirconia } \\
\text { (Y-TZP) }\end{array}$} & M & $596.59(57.18)$ & $505.39(75.88)$ & $536.48^{\mathrm{A}}[500.94-573.89]$ & $8.01^{\mathrm{A}}[5.07-10.78]$ & $1.79^{\mathrm{A}}(0.16)$ & $11.21^{\mathrm{A}}(1.07)$ \\
\hline & MP & $954.71(104.29)$ & $843.42(117.00)$ & $894.50^{\mathrm{B}}[836.52-955.45]$ & $8.19^{\mathrm{A}}[5.19-11.03]$ & $0.18^{\mathrm{B}}(0.03)$ & $1.71^{\mathrm{B}}(0.37)$ \\
\hline
\end{tabular}

Using the data of the M groups $(n=20)$, the roughness and the biaxial flexural fatigue strength values obtained for each set of burs were compared with the Student's t-tests $(\alpha=0.05)$. Spearman correlation coefficients $\left(\mathrm{r}_{\mathrm{s}}\right)(\alpha=0.05)$ were calculated to investigate the influence of the machining order in the roughness surface and in the biaxial flexural fatigue strength for each type of ceramic material, considering the set of burs separately.

\section{Results}

The step-load profiles of all ceramic materials showed that the MP groups failed under higher load ranges than the M groups, as indicated in Fig. 2. Machining resulted in significantly higher values of roughness and lower values of characteristic flexural fatigue strength when compared to the machining followed by polishing groups (Table 2). The greatest reduction in the characteristic flexural fatigue strength from MP to M was observed in Y-TZP (40\%), followed by lithium disilicate (33\%), and leucite glass ceramic (29\%). The Weibull modulus was similar for the conditions M and MP in all ceramics investigated.

The FESEM images indicate that machining induced defects in all ceramics investigated and that polishing was effective in removing these defects (Fig. 3). This can be verified by the reduction in the roughness (Ra values) after polishing: $94 \%$ for leucite, $92 \%$ for lithium disilicate and $89 \%$ for Y-TZP.

Student's t-test showed differences in the roughness values between the two sets of diamond burs used in the machining of leucite glass ceramic and Y-TZP discs. The fatigue strength of Y-TZP samples was also significantly influenced by the pair of burs (Table 3).

The correlation between machining order and roughness/flexural fatigue strength depended on the ceramic material and on the set of burs (Table 3). For leucite and lithium disilicate specimens, the Spearman coefficient indicated a sig- nificantly high [46] correlation between machining order and Ra just for one of the two sets of burs used. Again, regarding machining order and flexural fatigue strength, a significantly high [46] correlation was found in leucite and Y-TZP specimens for just one of the sets of burs.

\section{Discussion}

In the present study, CAD/CAM machining (M groups) introduced defects in the ceramic surface (Fig. 3), increasing surface roughness and significantly reducing the characteristic flexural fatigue strength of all ceramics investigated, when compared to the groups where the surface defects were removed by polishing (MP groups). Therefore, the experimental hypothesis was accepted.

An understanding about the extent of CAD/CAM machining effects on the mechanical behavior of ceramics with different microstructures is very important since the fracture strength of these materials is sensitive to the presence of defects [20]. These defects can be considered especially critical when located at the cementation surface of a ceramic crown due to the concentration of tensile stress in this area, which may predispose the all-ceramic restoration to clinical fractures [19]. The cervical margin of a crown may also be considered a critical zone $[47,48]$. As it usually presents a thinner structure, which is difficult for bur access, defects may be introduced by machining, contributing to initiate the failure, as indicated in some fractographic studies of clinically failed all-ceramic restorations $[25,26,49]$.

Leucite- and lithium disilicate-based glass ceramics are available for the hard machining process, which implies that the restoration is milled from an industrial, densely sintered block [1], and may require higher removal forces in machining [50]. In the present study, machining reduced the characteristic flexural fatigue strength of leucite glass 


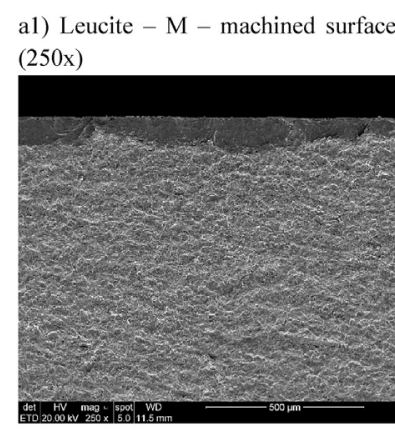

b1) Lithium disilicate $-\mathrm{M}$ - machined surface $(250 \mathrm{x})$

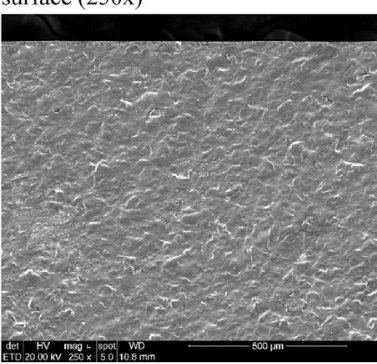

c1) Y-TZP - M - machined surface (250x)

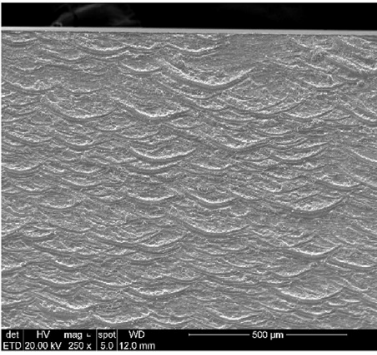

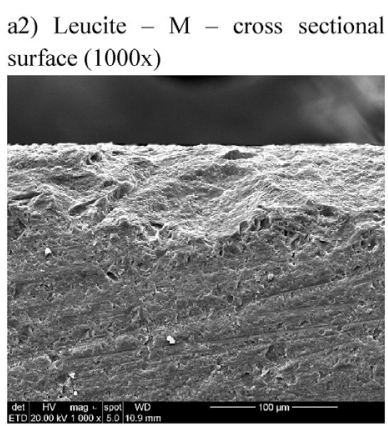

b2) Lithium disilicate $-\mathrm{M}-$ cross sectional surface $(1000 \mathrm{x})$

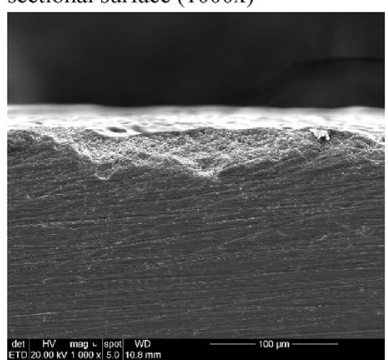

c2) Y-TZP - M - cross sectional surface $(1000 \mathrm{x})$

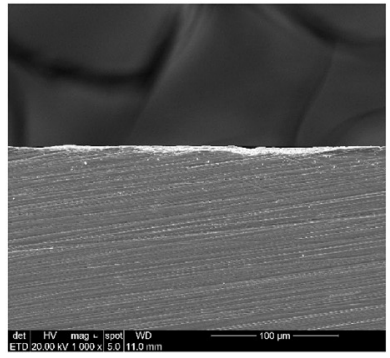

a3) Leucite - MP - machined and polished surface $(250 \mathrm{x})$

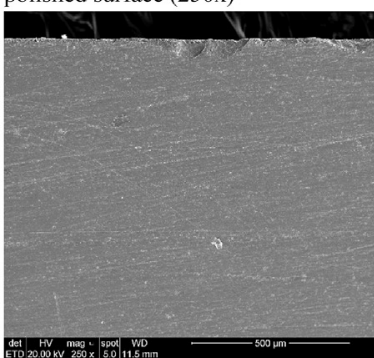

b3) Lithium disilicate - MP machined and polished surface $(250 \mathrm{x})$

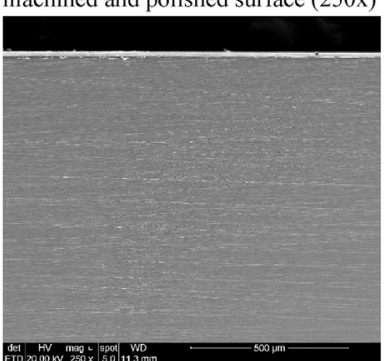

c3) Y-TZP - MP - machined and polished surface $(250 \mathrm{x})$

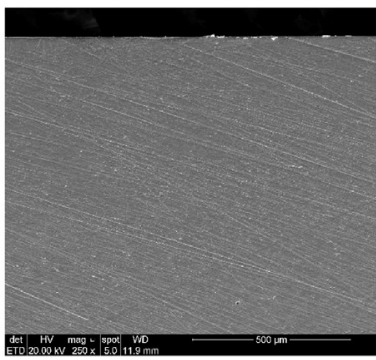

a4) Leucite - MP - cross sectional surface $(1000 x)$

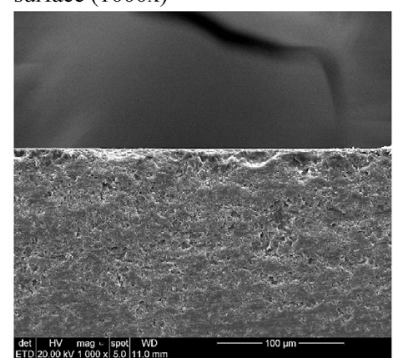

b4) Lithium disilicate - MP - cross sectional surface $(1000 \mathrm{x})$

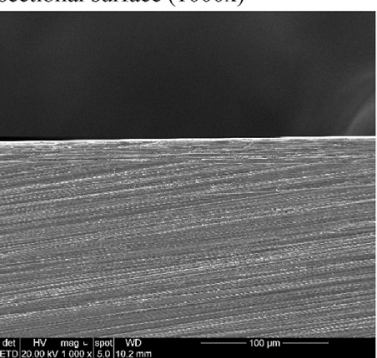

4) Y-TZP - MP - cross sectiona surface $(1000 x)$

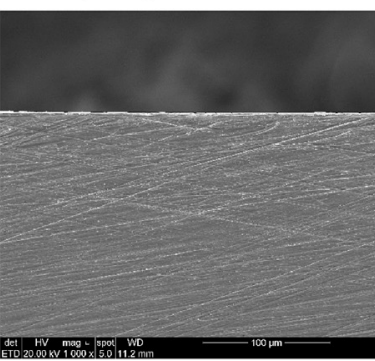

Fig. 3 - FESEM images of the machining (M) and machining followed by polishing (MP) surface for each ceramic material. Note that $M$ resulted in a rough surface, with the introduction of surface defects. Polishing appeared effective in removing these defects.

ceramic and lithium disilicate by approximately $29 \%$ and $33 \%$, respectively, when compared to the MP condition. Lithium disilicate ceramics are machined in the "blue stage", prior to full crystallization, which contains lithium metasilicate $\left(\mathrm{Li}_{2} \mathrm{SiO}_{3}\right)$ crystals. In this stage, the ceramic is easy to machine [1] and exhibits moderate biaxial strength (130 MPa) [51]. After machining, the restorations are submitted to a heat treatment to ensure final crystallization into lithium disilicate, and to

Table 3 - Mean and standard deviation (SD) of roughness (Ra) and flexural fatigue strength for each set of burs used in the machining of leucite, lithium disilicate, and yttria-stabilized polycrystalline tetragonal zirconia (Y-TZP) machining $(\mathrm{M})$ groups. Spearman correlation coefficient $\left(\mathrm{r}_{\mathrm{s}}\right)$ between machining order and Ra; and between machining order and flexural fatigue strength.

\begin{tabular}{|c|c|c|c|c|c|c|c|}
\hline \multirow[t]{2}{*}{ Ceramic } & \multirow[t]{2}{*}{ Bur } & \multicolumn{3}{|c|}{$\mathrm{Ra}$} & \multicolumn{3}{|c|}{ Fatigue strength } \\
\hline & & $\begin{array}{l}\text { Mean (SD) - } \\
\mu \mathrm{m}\end{array}$ & $p$-Value & $\begin{array}{l}\mathrm{r}_{\mathrm{s}} \\
p \text {-Value }\end{array}$ & $\begin{array}{l}\text { Mean (SD) - } \\
\mathrm{MPa}\end{array}$ & $p$-Value & $\begin{array}{l}\mathrm{r}_{\mathrm{s}} \\
p \text {-Value }\end{array}$ \\
\hline \multirow[t]{2}{*}{ Leucite } & Set of Bur $1 \mathrm{n}=10$ & $1.73(0.86)$ & 0.000 & -0.880 .001 & $69.91(7.35)$ & 0.241 & 0.740 .013 \\
\hline & Set of Bur $2 n=10$ & $1.45(0.81)$ & & -0.210 .556 & $73.88(7.25)$ & & 0.440 .200 \\
\hline \multirow[t]{2}{*}{ Lithium disilicate } & Set of Bur $1 \mathrm{n}=9$ & $1.78(0.18)$ & 0.450 & 0.320 .406 & $179.36(13.16)$ & 0.114 & -0.070 .865 \\
\hline & Set of Bur $2 n=11$ & $1.84(0.18)$ & & 0.910 .000 & $190.82(16.88)$ & & -0.210 .537 \\
\hline \multirow[t]{2}{*}{ Y-TZP } & Set of Bur $1 \mathrm{n}=9$ & $1.67(0.10)$ & 0.001 & -0.630 .067 & $554.25(60.29)$ & 0.002 & 0.730 .025 \\
\hline & Set of Bur $2 n=11$ & $1.90(0.15)$ & & -0.470 .142 & $459.31(58.52)$ & & 0.500 .117 \\
\hline
\end{tabular}


improve its flexural strength $(360 \mathrm{MPa})[51]$. This heat treatment is likely to reduce the extent of the residual stresses from machining and ensure the development of a microstructure composed of interlocked lithium disilicate crystals [4]. However, the damage introduced by machining was still present after the heat treatment, as seen in the FESEM images (Fig. 3), negatively affecting the characteristic fatigue strength of the material.

Y-TZP restorations are commonly milled from partially sintered blocks, in a process called soft machining, and then sintered at high temperature. The restoration is milled at a larger size to compensate for the volume shrinkage that will occur during sintering (approximately 20-25\%) [10]. In the present study, the greatest difference between the MP and M groups was evident for the Y-TZP ceramic, milled in a partially sintered stage, where machining reduced the material's characteristic flexural fatigue strength by $40 \%$.

Therefore, an important finding of this study was that, despite the partially sintered blocks being softer and easier to mill, soft machining may also introduce damage to the ceramic surface, negatively affecting the material's flexural fatigue strength just as much as hard machining. Apart from this, the heat treatment performed on the Y-TZP ceramic to complete sintering appeared unable to eliminate the machining defects, which was consistent with the results of Kelly and Rungruanganunt [52], which found severe machining damage in zirconia implant abutments, manufactured by soft milling.

To assess the effects of machining on the fatigue behavior of ceramics with different microstructures, one group of each material (MP group) was submitted to a polishing procedure after machining, which removed $80 \mu \mathrm{m}$ from the machined surface to ensure for the removal of machining defects. Few studies have investigated the extent of the damage introduced by CAD/CAM machining on the ceramic surface. The reported values ranged from $9 \mu \mathrm{m}$ to $15 \mu \mathrm{m}$ for glass ceramic [33], and from $40 \mu \mathrm{m}$ to $60 \mu \mathrm{m}$ for feldspathic ceramics [29]. Therefore, we believe that the polishing protocol adopted in the present study, which removed a thickness of $80 \mu \mathrm{m}$ from the machined surface, was effective in removing the defects introduced by machining, as evident in the FESEM images and in the roughness analysis (Fig. 3, Table 2).

The literature reported Ra values, after machining in a CEREC inLab unit, of $1.37 \mu \mathrm{m}$ [31] and $1.47 \mu \mathrm{m}$ [53] for a leucitebased glass ceramic, and of $1.53 \mu \mathrm{m}$ and $1.20 \mu \mathrm{m}$ for Y-TZP samples machined by different sets of burs [54]. Roughness after machining may be influenced by the material's hardness and by the grit size of the tool [55]. The pattern of peaks and valleys introduced by machining with diamond burs was reported to be deeper for soft materials (a resin nanoceramic composite) than for hard materials (fine particle feldspar ceramic; resin-infiltrated ceramic), suggesting that special care should be taken in the selection of the diamond grit size to optimize the roughness of a milled surface [55].

Grinding with fine diamond discs ( $18 \mu \mathrm{m}$ grit size) induced smaller chip damage and lower strength deterioration than grinding with medium diamond discs $(75 \mu \mathrm{m}$ and $54 \mu \mathrm{m}$ grit size) in feldspathic and leucite glass ceramic [56]. Considering this, improvements in the machining systems, with the use of burs with smaller diamond grit size, should be investigated in future studies as an alternative for reducing the damage introduced by CAD/CAM machining.

Weibull modulus, a shape parameter that describes the relative spread of strength values in an asymmetrical distribution [44], did not differ significantly between $\mathrm{M}$ and MP conditions for each ceramic (Table 2). Therefore, machining did not affect the reliability of the ceramic materials, despite having introduced more critical defects, reducing the tensile strength at which fracture occurs.

The step-test method can be considered a versatile fatigue test. It consists of a time-varying load test, in which the specimens are subjected to successively higher stress levels in a predetermined number of cycles [57]. This methodology has been employed to investigate the fatigue resistance of restorative treatments, where the data are submitted to survival analysis, such as Kaplan Meier [58-60]. According to Collins [40], when the step-test data is acquired, they may be plotted on a probability plot, from which the mean fatigue strength and the standard deviation may be determined for the defined cyclic fatigue life (number of cycles in an individual load step). Considering that the strength data of brittle materials typically fit in the Weibull distribution [44], in the present study, the step-test data were analyzed via Weibull statistics, and the values of the characteristic fatigue strength and the Weibull modulus were calculated for a life time of 10,000 cycles. The disadvantages of this method lies in the unknown effects of latent damage that may be incurred while stepping up through the series of stress levels to reach the failure stress levels [40]. More recently, step-test have also been used to obtain reliability information about a restorative treatment in a shorter time $[61,62]$. In these studies, three stress profiles (mild, moderate, and aggressive) are usually employed to distribute failure across different step loads and to allow better statistic predictions [63].

The comparison of the mean strength values obtained in the monotonic and in the fatigue test (Table 2) showed that fatigue test resulted in lower values of flexural strength. The reduction in the material strength tended to be higher for glass ceramic groups (around 33\%-44\%) than for Y-TZP groups (around 15\%). Despite showing the lowest strength degradation when compared to the monotonic results, Y-TZP ceramic was the most affected by machining. A previous study [64] indicated a strength degradation (difference between monotonic and fatigue strength) of approximately $42.7 \%$ for Y-TZP, $53.4 \%$ for a CAD/CAM lithium disilicate, and $45.5 \%$ for a CAD/CAM feldspathic ceramic. The microstructure significantly influenced the slow crack propagation of the dental ceramics $[6,65]$. Polycrystalline ceramics presented a low susceptibility to slow crack propagation and low degradation over time, while porcelains showed the lowest values for resistance against crack propagation, resulting in high strength degradation over time [6]. These findings support the trends evident in the present study.

Significant differences were found for roughness and fatigue strength between the two sets of burs used in the machining of Y-TZP specimens, while for leucite specimens, the difference between the sets of burs was just evident for the roughness (Table 3). Differences in the Ra values and in the biaxial flexural strength were reported in a study that employed six pairs of burs for machining of feldspathic 
ceramic discs in a CEREC inLab MC XL ${ }^{\circledR}$ unit [66]. Different sets of burs also influenced the roughness of Y-TZP specimens, but did not affect the reliability of the Y-TZP restorations [54]. The correlation between machining order and roughness/flexural fatigue strength was also dependent on the set of burs used in the machining. Therefore, considering that the set of burs may influence the roughness and the strength of the ceramic, special care should be taken in future studies involving CAD/CAM machining to randomly distribute, among the experimental groups, specimens milled by different sets of burs, avoiding any possible confounding results related to the diamond milling tools.

For leucite and Y-TZP materials, the Spearman correlation coefficients indicated that, for a maximum of 20 machined specimens, a possible deterioration of the machining burs may have no deleterious effects on the ceramic fatigue strength, since there was a positive correlation between machining order and fatigue strength. The correlation between machining order and roughness was significant and negative for leucite, which revealed a trend toward decreasing roughness with increasing machining order. Conversely, for lithium disilicate, a positive correlation was found. Nevertheless, the increased roughness with the machining order did not impact the fatigue strength, since no significant correlation was found with the fatigue strength for this material.

One of the limitations of the present study was that the effect of the cementation procedures on the flexural fatigue strength of machined ceramic specimens, such as hydrofluoric acid etching and airborne sandblasting, was not evaluated. Furthermore, the effect of machining on luted ceramic specimens should be investigated in future studies, since resin cements could interact with the ceramic surface, resulting in a hybrid layer that would further affect the ceramic strength [67].

Finally, it is important to highlight that the polishing protocol adopted in the present study had just a methodological purpose of eliminating the machining defects. This protocol should not be extrapolated to clinical practice, since the polishing of the intaglio surface of an all-ceramic restoration, with a reduction of $80 \mu \mathrm{m}$ in thickness, would increase cement thickness and result in fit problems. Therefore, this study highlights the need for improving machining systems, and for developing milling protocols that induce less damage to the ceramic surface. Other machining variables, such as the diamond grit size and the feed rate should be investigated to understand their effect on the machined surface.

\section{Conclusions}

CAD/CAM machining negatively affected the flexural fatigue strength of ceramics with different microstructures and resulted in higher values of roughness. The greatest reduction in the fatigue strength due to machining was observed in Y-TZP (40\%), followed by lithium disilicate (33\%), and leucite glass ceramic (29\%), suggesting that either machining of partially sintered ceramics or machining of fully sintered ceramics may be deleterious to their flexural fatigue strength.

\section{Acknowledgments}

The authors are thankful to Ivoclar Vivadent for donating some ceramic blocks used in this study; Arie Werner for manufacturing the test devices; CAPES/NUFFIC by the PhD scholarship.

\section{REFERENCES}

[1] Denry I, Holloway JA. Ceramics for dental applications: a review. Materials (Basel) 2010;3:351-68.

[2] Li RWK, Chow TW, Matinlinna JP. Ceramic dental biomaterials and CAD/CAM technology: state of the art. J Prosthodont Res 2014;58:208-16.

[3] Denry I, Kelly JR. Emerging ceramic-based materials for dentistry. J Dent Res 2014;93:1235-42.

[4] Denry I. How and when does fabrication damage adversely affect the clinical performance of ceramic restorations? Dent Mater 2013;29:85-96.

[5] Quinn JB, Sundar V, Lloyd IK. Influence of microstructure and chemistry on the fracture toughness of dental ceramics. Dent Mater 2003;19:603-11.

[6] Borba M, de Araújo MD, Fukushima KA, Yoshimura HN, Cesar PF, Griggs JA, et al. Effect of the microstructure on the lifetime of dental ceramics. Dent Mater 2011;27:710-21.

[7] Apel E, Deubener J, Bernard A, Höland M, Müller R, Kappert $\mathrm{H}$, et al. Phenomena and mechanisms of crack propagation in glass-ceramics. J Mech Behav Biomed Mater 2008;1: 313-25.

[8] Ivoclar Vivadent. IPS Empress ${ }^{\circledR}$ CAD: instructions for uselabside; 2006.

[9] Ivoclar Vivadent. IPS. e.max CAD: instructions for uselabside; 2009.

[10] Denry I, Kelly JR. State of the art of zirconia for dental applications. Dent Mater 2008;24:299-307.

[11] Zarone F, Russo S, Sorrentino R. From porcelain-fused-to-metal to zirconia: clinical and experimental considerations. Dent Mater 2011;27:83-96.

[12] Chevalier J, Gremillard L, Deville S. Low-temperature degradation of zirconia and implications for biomedical implants. Annu Rev Mater Res 2007;37:1-32.

[13] Beuer F, Stimmelmayr M, Gueth JF, Edelhoff D, Naumann M. In vitro performance of full-contour zirconia single crowns. Dent Mater 2012;28:449-56.

[14] Nakamura K, Harada A, Kanno T, Inagaki R, Niwano Y, Milleding P, et al. The influence of low-temperature degradation and cyclic loading on the fracture resistance of monolithic zirconia molar crowns. J Mech Behav Biomed Mater 2015;47:49-56.

[15] Belli R, Petschelt A, Hofner B, Hajto J, Scherrer SS, Lohbauer U. Fracture rates and lifetime estimations of CAD/CAM all-ceramic restorations. J Dent Res 2016;95:67-73.

[16] Sailer I, Makarov NA, Thoma DS, Zwahlen M, Pjetursson BE. All-ceramic or metal-ceramic tooth-supported fixed dental prostheses (FDPs)? A systematic review of the survival and complication rates. Part I: single crowns (SCs). Dent Mater 2015;31:603-23.

[17] Pjetursson BE, Sailer I, Makarov NA, Zwahlen M, Thoma DS. All-ceramic or metal-ceramic tooth-supported fixed dental prostheses (FDPs)? A systematic review of the survival and complication rates. Part II: multiple-unit FDPs. Dent Mater 2015;31:624-39.

[18] Heintze SD, Rousson V. Fracture rates of IPS Empress all-ceramic crowns: a systematic review. Int J Prosthodont 2010;23:129-33. 
[19] Kelly JR, Giordano R, Pober R, Cima MJ. Fracture surface analysis of dental ceramics: clinically failed restorations. Int J Prosthodont 1990;3:430-40.

[20] Kelly JR. Perspectives on strength. Dent Mater 1995;11:103-10.

[21] Quinn JB, Quinn GD, Kelly JR, Scherrer SS. Fractographic analyses of three ceramic whole crown restoration failures. Dent Mater 2005;21:920-9.

[22] Thompson JY, Anusavice KJ, Naman A, Morris HF. Fracture surface characterization of clinically failed all-ceramic crowns. J Dent Res 1994;73:1824-32.

[23] May LG, Kelly JR, Bottino MA, Hill T. Effects of cement thickness and bonding on the failure loads of CAD/CAM ceramic crowns: multi-physics FEA modeling and monotonic testing. Dent Mater 2012;28:e99-109.

[24] Kelly JR. Clinically relevant approach to failure testing of all-ceramic restorations. J Prosthet Dent 1999;81:652-61.

[25] Øilo M, Gjerdet NR. Fractographic analyses of all-ceramic crowns: a study of 27 clinically fractured crowns. Dent Mater 2013;29:e78-84.

[26] Øilo M, Hardang AD, Ulsund AH, Gjerdet NR. Fractographic features of glass-ceramic and zirconia-based dental restorations fractured during clinical function. Eur J Oral Sci 2014;122:238-44.

[27] Marshall DB, Evans AG, Khuri Yakub TB, Tien JW, Kino GS. The nature of machining damage in brittle materials. Proc $\mathrm{R}$ Soc Lond A Math Phys Sci 1983;385:461-75.

[28] Zhang GM, Satish KG, Ko WF. The mechanics of material removal mechanisms in machining ceramics. Tech Rep TR 94-22rl Inst Syst Res 1994.

[29] Sindel J, Petschelt A, Grellner F, Dierken C, Greil P. Evaluation of subsurface damage in CAD/CAM machined dental ceramics. J Mater Sci Mater Med 1998;9:291-5.

[30] Rekow D, Thompson VP. Near-surface damage - a persistent problem in crowns obtained by computer-aided design and manufacturing. Proc Inst Mech Eng Part H 2005;219:233-43.

[31] Fraga S, Valandro LF, Bottino MA, May LG. Hard machining, glaze firing and hydrofluoric acid etching: do these procedures affect the flexural strength of a leucite glass-ceramic? Dent Mater 2015;31:e131-40.

[32] Wang H, Aboushelib MN, Feilzer AJ. Strength influencing variables on CAD/CAM zirconia frameworks. Dent Mater 2008;24:633-8.

[33] Kelly JR, Lüthy H, Gougoulakis A, Pober RL, Mörmann WR. Machining effects on feldspathic porcelain and glass ceramic: fractographic analysis. In: Mörmann WH, editor. International symposium on computer restorations. Quintessence Publishing; 1991. p. 253-73.

[34] Wiskott HW, Nicholls JI, Belser UC. Stress fatigue: basic principles and prosthodontic implications. Int J Prosthodont 1995;8:105-16.

[35] Gonzaga CC, Cesar PF, Miranda WG, Yoshimura HN. Slow crack growth and reliability of dental ceramics. Dent Mater 2011;27:394-406.

[36] VITA Zahnfabrik. VITA In-Ceram ${ }^{\oplus}$ YZ: working instructions. Germany. Data of issue: September 2012.

[37] International Organization For Standardization. ISO 4287: Geometrical product specifications (GPS) - surface texture: profile method, terms, definitions and surface textureparameters; 1997.

[38] International Organization For Standardization. ISO 6872: Dentistry - ceramicmaterials; 2008.

[39] Belli R, Wendler M, de Ligny D, Cicconi MR, Petschelt A, Peterlik H, et al. Chairside CAD/CAM materials. Part 1: measurement of elastic constants and microstructural characterization. Dent Mater 2017;33:84-98.
[40] Collins JA. Fatigue testing procedures and statistical interpretations of data. In: Failure of materials in mechanical design. 2nd ed. John Wiley \& Sons; 1993. p. 374-92.

[41] Nicholas T. Accelerated test techniques. In: High cycle fatigue: a mechanics of materials perspective. Oxford: Elsevier Ltd; 2006. p. 70-134.

[42] Weibull W. A statistical theory of the strength of materials. R Swedish Inst Eng Res 1939;151:1-45.

[43] Weibull W. A statistical distribution function of wide applicability. J Appl Mech 1951;18:293-7.

[44] Quinn JB, Quinn GD. A practical and systematic review of Weibull statistics for reporting strengths of dental materials. Dent Mater 2010;26:135-47.

[45] ENV 843-4. Advanced technical ceramics - monolithic ceramics - mechanical tests at room temperature - part 5: statistical analysis. European Standards; 1996.

[46] Mukaka MM. Statistics corner: a guide to appropriate use of correlation coefficient in medical research. Malawi Med J 2012;24:69-71.

[47] Øilo M, Kvam K, Reisegg K, Gjerdet NR. The effects of margin curvature on load at fracture of ceramic crowns. Int J Prosthodont 2015;28:357-9.

[48] Øilo M, Kvam K, Tibballs JE, Gjerdet NR. Clinically relevant fracture testing of all-ceramic crowns. Dent Mater 2013;29:815-23.

[49] Øilo M, Quinn GD. Fracture origins in twenty-two dental alumina crowns. J Mech Behav Biomed Mater 2016;53:93-103.

[50] Song X, Ren H, Yin L. Machinability of lithium disilicate glass ceramic in in vitro dental diamond bur adjusting process. J Mech Behav Biomed Mater 2016;53:78-92.

[51] Ivoclar Vivadent. IPS. e.max CAD: scientificdocumentation; 2009.

[52] Kelly JR, Rungruanganunt P. Fatigue behavior of computer-aided design/computer-assisted manufacture ceramic abutments as a function of design and ceramics processing. Int J Oral Maxillofac Implants 2016;31:601-9.

[53] Aurélio IL, Fraga S, Dorneles LS, Bottino MA, May LG. Extended glaze firing improves flexural strength of a glass ceramic. Dent Mater 2015;31:e316-24.

[54] Corazza PH, de Castro HL, Feitosa SA, Kimpara ET, Della Bona A. Influence of CAD-CAM diamond bur deterioration on surface roughness and maximum failure load of Y-TZP-based restorations Influence of CAD-CAM diamond bur deterioration on surface roughness and maximum failure load of Y-TZP-based restorations. Am J Dent 2015;28:95-9.

[55] Lebon N, Tapie L, Vennat E, Mawussi B. Influence of CAD/CAM tool and material on tool wear and roughness of dental prostheses after milling. J Prosthet Dent 2015;114:236-47.

[56] Curran P, Cattani-lorente M, Wiskott HWA, Durual S, Scherrer SS. Grinding damage assessment for CAD-CAM restorative materials. Dent Mater 2017;33:294-308.

[57] Mettas A, Vassiliou P. Modeling and analysis of time-dependent stress accelerated life data. Proceedings of the annual reliability and maintainability symposium 2002:343-8.

[58] Batalha-Silva S, De Andrada MAC, Maia HP, Magne P. Fatigue resistance and crack propensity of large MOD composite resin restorations: direct versus CAD/CAM inlays. Dent Mater 2013;29:324-31.

[59] Güth J-F, Edelhoff D, Goldberg J, Magne P. CAD/CAM polymer vs direct composite resin core buildups for endodontically treated molars without ferrule. Oper Dent 2016;41: 53-63.

[60] Magne P, Carvalho AO, Bruzi G, Giannini M. Fatigue resistance of ultrathin CAD/CAM complete crowns with a 
simplified cementation process. J Prosthet Dent 2015;114:574-9.

[61] Basso GRR, Moraes RRR, Borba M, Duan Y, Griggs JAA, Della Bona A. Reliability and failure behavior of CAD-on fixed partial dentures. Dent Mater 2016;32:624-30.

[62] Shembish FA, Tong H, Kaizer M, Janal MN, Thompson VP, Opdam NJ, et al. Fatigue resistance of CAD/CAM resin composite molar crowns. Dent Mater 2016;32:499-509.

[63] Bonfante EA, Coelho PG. A critical perspective on mechanical testing of implants and prostheses. Adv Dent Res 2016;28:18-27.

[64] Belli R, Geinzer E, Muschweck A, Petschelt A, Lohbauer U. Mechanical fatigue degradation of ceramics versus resin composites for dental restorations. Dent Mater 2014;30:424-32.

[65] Ramos NC, Campos TMB, de La Paz IS, Machado JPB, Bottino MA, Cesar PF, et al. Microstructure characterization and SCG of newly engineered dental ceramics. Dent Mater 2016;32:870-8.

[66] Addison O, Cao X, Sunnar P, Fleming GJP. Machining variability impacts on the strength of a 'chair-side' CAD-CAM ceramic. Dent Mater 2012;28:880-7.

[67] Addison O, Marquis PM, Fleming GJP. Quantifying the strength of a resin-coated dental ceramic. J Dent Res 2008;87:542-7. 